\title{
Prácticas de crianza, legado cultural afrodescendiente. Narrativas de mujeres afrovenezolanas*
}

\author{
Diónys Cecilia Rivas Armas \\ Fundación Escuela Venezolana de Planificación, Caracas, Venezuela \\ dionysrivasarmas@gmail.com \\ Ismenia de Lourdes Mercerón \\ Universidad Nacional Experimental Simón Rodríguez, Maracay, Venezuela \\ nenajabamiah84@gmail.com
}

\section{RESUIMEN}

Las nodrizas, ayas, nanas, madres o amas de leche tenían a su cargo, durante la colonización y esclavitud en el Abya Yala y El Caribe, el cuidado y crianza de los hijos e hijas de los amos, y juntos asentaron el proceso de apego, vínculo afectivo y cultural. El propósito del presente estudio es visibilizar, desde las narrativas de mujeres afrovenezolanas, las prácticas de crianzas del legado cultural afrodescendiente que hoy día se continúan conservando, lo cual pasa a ser patrimonio inmaterial espiritual vivificado en los enclaves afrovenezolanos y los espacios urbanos. El estudio se abordó bajo la metodología cualitativa, que complementa el método etnográfico y biográfico-narrativo. Se hizo uso de grabaciones y encuentros conversacionales con cuatro mujeres afrovenezolanas elegidas intencionalmente, dos de ellas son las autoras del presente estudio. Las prácticas de crianzas, más que un hecho narrativo de la historia venezolana, son una práctica ancestral cotidiana donde las mujeres han sido y seguirán siendo las protagonistas, transmisoras de valores, preservación de las concepciones religiosas y eje central del núcleo familiar.

Palabras clave: mujeres afrovenezolanas; prácticas de crianza; narrativas; nodrizas y ayas.

Cómo citar: Rivas, D. y Mercerón, I. (2020). Prácticas de crianza, legado cultural afrodescendiente. Narrativas de mujeres afrovenezolanas. Ciencias Sociales y Educaciòn, 9 (18), 57-84. https://doi. org/10.22395/csye.v9n18a3

Recibido: 27 de enero de 2020.

Aprobado: 15 de marzo de 2020. 


\section{Uphringing practices, an Afro-Sescendant Cultural Legacy. Afro-Venezuelan Women Narratives}

\section{ABSTRACT}

The nurses, ayas, nanas, mothers or wet nurses had at their charge, during the colony and slavery periods in the Abya Yala and the Caribbean, the care and upbringing of the sons and daughters of the masters and together they settled the process of attachment, both an affective and cultural bond. The purpose of this article is to make visible, from the narratives of the Afro-Venezuelan women, the upbringing practices of the Afro-descendant cultural legacy that are currently preserved and, thus, have become a spiritual immaterial heritage that is vivified in the AfroVenezuelan enclaves and the urban spaces. The study was performed with a qualitative methodology that is complemented by the ethnographic and biographical-narrative approaches. The research made use of conversational meetings with four AfroVenezuelan women intentionally selected; two of them are the writers of this article. The upbringing practices, more than a narrative fact of Venezuelan history, are an ancestral and quotidian practice where women have been and will keep being the protagonists, transmitter of values, preservation of the religious conceptions and central axis of the family group.

Keywords: Afro-Venezuelan mothers; upbringing practices; narratives; wet nurses, ayas.

\section{Práticas parentais, legado cultural afro-descendente. Narrativas de mulheres afro-venezuelanas}

\section{RESUMO}

Durante a colonização e a escravidão em Abya Yala e no Caribe, as criadeiras ou amas de leite ficavam encarregadas de cuidar e criar os filhos e filhas dos senhores e, juntas, estabeleceram um processo de apego, vínculo afetivo e cultural. O objetivo deste estudo é visibilizar, a partir das narrativas das mulheres afro-venezuelanas, as práticas parentais do legado cultural afrodescendente que perpetuam até hoje, tornando-se um patrimônio imaterial que é refletido tanto nas dificuldades enfrentadas pela população afro-venezuelana quanto nos espaços urbanos. A metodologia qualitativa utilizada neste estudo foi complementada pelo método etnográfico e biográfico-narrativo. Conversamos com quatro mulheres afro-venezuelanas escolhidas intencionalmente (duas delas são as autoras do presente estudo). Essas conversas foram gravadas e utilizadas neste estudo. As práticas parentais, mais do que um fato narrativo da história venezuelana, são uma prática ancestral cotidiana onde as mulheres foram e continuarão sendo as protagonistas, transmissoras de valores, responsáveis pela preservação de concepções religiosas e eixo central do núcleo familiar.

Palavras-chave: amas de leite; criadeiras; mulheres afro-venezuelanas; narrativas; práticas parentais. 
Las mujeres que vienen del continente que parió la humanidad, en un momento histórico, fueron arrancadas de sus territorios. Ya en la colonia, hermana, hija, sobrina, amiga, prima, esposa, madrina, tía, abuela, ahijada; nodriza, libertaria, mamá, luz; abogada para sí misma y su familia, en esta región de América, en tanto que ponen las semillas de su origen, sus procedencias, lenguas, saberes y haceres en niños y niñas, también trajeron el legado de parir libertad. (Vergara y Cosme, 2018)

\section{Introducción}

Las prácticas de crianza ancestrales están determinadas por las costumbres y tradiciones que se ajustan a las condiciones ecológicas, culturales, sociales y territoriales, las cuales están integradas a la vida diaria y constituyen una respuesta de aprendizaje a las necesidades del niño y la niña para que crezcan y se desarrollen con experiencias afectivas y cognitivas en función de las concepciones y creencias de la persona que está a cargo de su crianza.

El papel de las nodrizas durante la colonización y proceso de esclavización en el Abya Yala y el Caribe permitieron instaurar prácticas de crianza que, bajo las circunstancias sociales, culturales y económicas, propició la transferencia de símbolos, códigos y tradiciones que se reconcilian con las prácticas de cuidado de los pueblos del África. Estas prácticas han permanecido a lo largo del tiempo como una sabiduría ancestral y una acción que favorece el desarrollo de pensamientos y sentimientos durante la primera infancia y determina los procesos emocionales y psicológicos en la adultez.

Las nodrizas, nanas o amas de leche que tenían a su cargo el cuidado y crianza de los hijos e hijas de los amos, asentaron el proceso de apego, vínculo afectivo y cultural a través de la permanente protección y proximidad física y espiritual entre la madre de leche y el recién nacido mientras lo amamantaban, arrullaban con canciones de cuna e intercambiaban miradas en ese proceso de nutrir el cuerpo y el alma.

Amamantar en el África occidental y central es fundamental en las concepciones culturales que le daban a la madre, como transmisora de valores, preservación de las concepciones religiosas y eje central del núcleo familiar. Al respecto, Velásquez (2006) señala: "La experiencia de convivir en familias extensas, dentro de las cuales las madres tenían injerencia en la crianza de los hijos aunque no necesariamente fueran propios, posibilitó que la experiencia de amamantar fuera una práctica comunitaria" (p. 185).

Desde esta práctica se establecía una conexión de los procesos de crianza y el sentido de pertenencia con la comunidad que constituía el núcleo familiar para 
la transmisión de valores, manifestaciones, relatos y creencias que propiciaban el desarrollo cultural de las hijas e hijos, donde la sabiduría se nutre del lactar que emana de muchas madres de la comunidad, como bien lo expresa el Inca Garcilaso de la Vega (1943): "yo escrivo [sic], como otras vezes [sic] he dicho, lo que mamé en la leche y vi y oí a mis mayores" (p. 175).

Esta dinámica colectiva es conservada por muchas comunidades afrodescendientes, donde las familias extendidas son la fuerza y condición que contribuye a la formación de los niños y las niñas. Las creencias, valores y costumbres se transmiten de manera dinámica y de generación en generación a través de la oralidad. Esta experiencia fue estudiada en las comunidades urbanas de los municipios de Montería y Moñitos del departamento de Córdoba (Colombia) por investigadores de la Universidad Católica Luis Amigó. Los investigadores Mery Cardona Oviedo y Víctor Terán-Reales (2017), dentro de sus conclusiones, señalan:

La familia extensa o extendida considerada uno de los más importantes legados africanos en la diáspora americana, y cuyos valores permitieron su adaptación y supervivencia en el Nuevo Mundo, hoy en los afrodescendientes tiene presencia en centros urbanos como la ciudad de Montería y de Moñitos. En estos hogares juegan un rol importante los abuelos como centro aglutinante de los miembros familiares y el decisivo papel que desempeñan en la crianza de los hijos e hijas. (p. 27)

Por otro lado, es importante señalar que los propios hijos e hijas de las mujeres esclavizadas no disfrutaron de este proceso de crianza durante la colonia debido a la separación temprana y forzada para ejercer como nodrizas alejada de los suyos y por las largas horas cuidando a otros. Así, se esforzaban doblemente para mantener lazos con ellos, ya que sufrieron un control más directo sobre sus vidas, desintegración de su propia familia y aislamiento con respecto a su comunidad. En este sentido, Ramos Guédez señala (2019): "sacrificando en muchas ocasiones a sus propios niños o niñas; sin olvidar en ningún momento su labor educativa en la transmisión de tradiciones, mitos, leyendas y otras expresiones culturales originarias del continente africano" (p. 61).

A pesar de esta situación, se esforzaron en gran medida en dar a conocer a sus hijos e hijas de vientre, crianza y leche las tradiciones, costumbres, conocimientos medicinales y estéticos sobre la creación y herencia de la genealogía de su grupo étnico.

Por ello, el propósito del presente estudio es mostrar, desde las narrativas de mujeres afrovenezolanas, las prácticas de crianzas del legado cultural afrodescendiente que hoy día se continúan conservando. La importancia radica en que estas prácticas, que aún se conservan, constituyen el patrimonio inmaterial espiritual vivificado en los enclaves afro y los espacios urbanos. Para la 
construcción del presente artículo se realizó la revisión de fuentes documentales, digitales, así como de fuentes primarias: textos y entrevistas personales.

El abordaje metodológico se realizó mediante la investigación cualitativa, descriptiva de campo y complementariedad de método: etnográfico y la biográfica-narrativa, la cual se ha legitimado como una forma de construir conocimiento en la investigación educativa y social (Bolívar, Segovia y Fernández, 2001) a partir de la consulta de fuentes primarias y secundarias. El abordaje de las entrevistas permitió interpretar vivencias y experiencias en las prácticas de crianzas. Hacemos la salvedad que las mujeres entrevistadas son nombradas bajo su autorización con su nombre de pila.

\section{Relatos de nodrizas, ayas, parteras y curanderas durante la colonia en Venezuela}

Sin duda, la colonización y conquista de nuestro continente y el Caribe, afianzaron los procesos de subordinación, opresión y discriminación hacia las mujeres. María del Mar Alvárez (2010) en su texto Historia de lucha de la mujer Venezolana, nos relata cómo las indígenas y las esclavizadas negras son sometidas a una estructura de poder racial y social para la hegemonía y dominación de género: "Con respecto a nuestro país podemos decir que la subordinación y la discriminación de las mujeres se inician con la conquista y colonización española, que imponen una familia patriarcal transformando la existente entre nuestros indígenas" (p. 18).

Esta idea es desarrollada por la investigadora venezolana Iraida VargasArenas (2010), donde nos explica cómo la colonia legitimó la subvaloración del trabajo de las mujeres, su inferioridad y se establecieron estereotipos sobre su debilidad, irracionalidad y vulnerabilidad frente a los hombres. En este sentido, afirma Iraida Vargas-Arenas:

\footnotetext{
Durante la colonia se institucionalizó la ideología patriarcal que nos legó un nuevo repertorio de estereotipos sobre las mujeres, los cuales variaban según las clases sociales y estaban basados en las ideas aristotélicas; esos estereotipos nos han marcado a las mujeres como seres débiles, irreflexivos, emocionales, inferiores a los hombres, siempre necesitadas de representación masculina. (p. 41)
}

Por tanto, durante la colonia muchas de las esclavizadas indígenas y africanas no solo eran instrumentos de explotación en el ámbito de la producción o el trabajo, sino de la explotación sexual y violencia material, donde el cuerpo, en particular el cuerpo de las africanas, se convirtió en mercancía. En este contexto, Duno-Gottberg (2014) afirma: "El cuerpo de la mujer esclava era entonces fuente de trabajo, lugar donde se reproducía el capital del ingenio (a través del alumbramiento de nuevos esclavos) y, finalmente fuente de placer para el amo" (p. 68). Según Meillassoux (1979), las mujeres esclavizadas de origen africano 
se les denominaba "esclavo agrario o siervo" (p. 11) durante la colonia. Se dedicaban al trabajo agrícola y eran controladas económicamente por los amos, quienes abusaban sexualmente de ellas y de los hijos e hijas producto de esta violación: "pasaban a engrosar la fuerza de trabajo propiedad de los señores" (Vargas-Arenas, 2019, p. 136). Igualmente, el investigador venezolano Acosta (1984) describe esta situación:

Cuando las esclavas eran dedicadas al servicio doméstico llegaban a constituir problema especial para las dueñas, pues éstas [sic] debían cuidar diversas posibilidades: la de que los propios amos, o sus hijos varones, llegasen a tener relaciones con las que fuesen atractivas [...] como la clase de los amos no era responsable por ningún daño a los esclavos, los abusos sexuales no tenían límite [...]. En realidad ninguna esclava podía negarse a los requerimientos del amo o de sus hijos adolescentes o adultos. (pp. 201-202)

Efectivamente, sus actividades estaban destinadas básicamente al ámbito privado y "actividades propias de su sexo", como lo son el servicio doméstico (tareas reproductivas para el cuidado, procreación y placer), tareas de limpieza (lavar, cocinar, planchar), buscar leña, cargar el agua y en especial cuidar y amamantar a las niñas y niños de las familias mantuanas y grandes cacaos. Así lo reafirma María del Mar Álvarez (2010):

La explotación de la fuerza de trabajo de las esclavas estuvo encaminada en dos direcciones: a labores agrícolas y al servicio doméstico (a este último se dedicó un sector considerable). En cumplimiento de dichas tareas fueron lavanderas, cocineras, aseadoras de la casa, planchadoras, actuaban como asistentes de las jóvenes y en general de las mujeres de la familia. Cuidaban a todos los enfermos, actuaban como curanderas y preparaban bebedizos sanadores. Cabe destacar como oficios importantes el de ayas y nodrizas de los(as) hijos(as) de los amos. (p. 28)

Es importante señalar que las mujeres esclavizadas que se dedicaban al servicio doméstico, se sometían a fuertes limitaciones en relación con la conformación de su propia familia, la consolidación de relaciones de pareja (matrimonios) y a la participación en actividades sociales, festejos y cofradías, ya que existía una mayor vigilancia y se exponían más directamente a castigos y malos tratos. La condición de objeto y de apropiación otorgada a las mujeres africanas las sometió a un control continuo que les negaba la posibilidad de tomar decisiones en cuanto a su vida, sexualidad, autonomía para conformar su propia familia y decidir sobre los hijos e hijas que deseaban tener y mucho menos cuidarlos. En este sentido, dice Vargas-Arenas (2019):

la esclavitud supuso para las mujeres esclavas la negación de cualquier derecho en lo que atañe a su sexualidad, ya que no sólo [sic] no podían escoger pareja, sino que incluso les estaba vedada la posibilidad de reproducirse biológicamente con el individuo de su escogencia. (p. 136) 
$\mathrm{Al}$ respecto, un relato recogido por Acosta (1984) en el que María Polonia, esclava de los herederos de don Francisco de Tovar en 1.799, declara sobre los castigos, maltratos y deseos de casarse:

En súplica a Ud. me dé mi papel de venta porque me hallo acosada del poco alimento que me dan mis amos, que es medio cuartico de casabe y caldo diario, sin más carne ni cosa que me ayude a mantener, ni tiempo para ganar un medio real que me pudiera servir para alimentarme. A eso se agrega el maltrato de mi persona, que me da lugar a buscar otro amo, pues bien lo manifiesta mi flaqueza y pies hinchados de estar en el cepo [...]. Ante Ud. expongo que hace días me hallo fugitiva de la casa de mis amos, porque habiendo pedido licencia y papel para solicitar otro amo, me lo han negado. El motivo que tengo para esta novedad es que quiero casarme con José Ramón, esclavo de mi ama Rosalía de la Madriz y en el poder de los amo que tengo no he de poder efectuar el matrimonio. (pp. 229 - 230)

En este sentido, como bien lo señalan diversas investigaciones, las mujeres negras y sus descendientes se sometían a realizar el trabajo doméstico en innumerables tareas que requerían mucho tiempo y dedicación: desde preparar los alimentos, ser cuidadoras, lavanderas y hasta ejercer como sobadoras y curanderas. Así lo cuenta Acosta (1984):

Contribuían al trabajo de la cocina, a la atención general de la casa, donde realizaban el llamado servicio de adentro, actuaban como asistentes de las niñas y jóvenes hijas de los amos. Atendían a sus aderezos, las cuidaban en las enfermedades, veían por los achaques de todos, acudiendo, cuando se necesitaba, con cataplasmas, agua caliente para los baños de pies y de asiento. Preparaban tisanas; emplastes bebedizos, y hasta practicaban oficio de algebristas, reduciendo torceduras y sobando descomposturas de las extremidades. (p. 201)

A partir del reciente trabajo de Iraida Vargas-Arenas (2019), expresa que durante la colonia: "las mujeres desempeñaron nuevas tareas sociales: como comadronas y médicas herbolarias, como recolectoras de plantas medicinales" (p. 66). Evidentemente, las mujeres africanas y sus descendientes desprendieron en el nuevo territorio todas sus experiencias de saberes ancestrales, sobre todo en el campo espiritual y medicinal, los cuales beneficiaron a toda la familia blanca, donde prestaban su servicio doméstico en condiciones de esclavización.

Sin embargo, las mujeres negras esclavizadas cumplieron un especial papel en el cuidado y crianza de los hijos e hijas de los amos durante la colonia, como nodrizas, ayas y como parteras. Se encargaban de atender los alumbramientos de las "amas blancas", amamantar, dar educación, atención y cuidado a los hijos e hijas de sus esclavizadores. Por tanto, desarrollar todas estas tareas implicaba la pérdida y abandono de sus propios hijos e hijas, y negarles a sus hijos e hijas la posibilidad de alimentarse de la leche de sus madres. Efectivamente, la influencia afectiva y amorosa de la aya y nodriza 
negra fue determinante en la constitución de la cultura y la formación de la personalidad básica del venezolano, Así lo afirma Acosta (2014a):

las negras eran parteras y ayas. Todo blanco llegaba al mundo en manos de la partera negra. Todavía duró esto hasta el primer cuarto del presente siglo. Y la aya, la criadora, siempre fue negra. Muchos blancos tenían sus hermanos de leche. (p. 173)

Sin duda, las niñas y niños criados por nodrizas de origen africano establecieron lazos de pertenencia, afectividad y cariño frente a sus mamás de leche, quienes se encargaban de alimentarlos, vestirlos, bañarlos y entretenerlos con cuentos, canciones, susurros y arrullos durante sus primeros años de vida. Esto lo podemos evidenciar en las muestras de agradecimiento ofrecidas por Bolívar a su nodriza Hipólita. A su hermano de leche Dionisio, hijo de Hipólita que luchó a su lado en la batalla de Carabobo, lo liberó de la esclavitud junto a su esclava María Jacinta Bolívar. Además, le fijó una pensión mensual a su amada nodriza en una carta que le escribió a su sobrino y apoderado, Anacleto Clemente, el 29 de Mayo de 1823. En esta carta hace referencia a varios asuntos familiares, dentro de los que se destaca la protección económica a su madre Hipólita a través de una pensión mensual de su propio peculio. Así escribe Simón Bolívar:

el otro día te mandé una libranza de mil quinientos pesos contra el arrendador de San Mateo para que pagasen a Antonia el valor de su pasaje. Ahora te mando una orden para que dicho arrendador pase mensualmente a tu madre cien pesos mensuales, y a la vieja Hipólita treinta para que se mantenga mientras viva. (Carrera, 1993, p. 240)

Estos hijos e hijas de leche representan el refugio y recuerdo de la tierra de estas mujeres que lograban ejercer esta práctica como herencia de su cuerpo, territorio y legado ancestral, que recorre la leche que emana de sus entrañas. El recorrido dulce que da vida representa un camino de libertad y esperanza; un camino que era contado por las nodrizas y ayas al recrear fabulosos personajes que prolongaban la vida que deseaban frente a la explotación, deshumanización y esclavización de sus vidas y de sus descendientes. Acosta (1984) señala:

Ellas, al amamantar, educaban; al cuidar a los párvulos depositaban cuentos pavorosos en sus oídos; sembraban en sus espíritus espantados grandes temores; miedo de fuerzas inmensas, que en realidad no eran sino las tremendas contradicciones de la sociedad colonial, encarnadas en la mente de los esclavos en seres fabulosos, incapacitados como estaban históricamente, para entender la estructura social en donde vivían. (p. 204)

Como bien lo expresa Vargas-Arenas (2019): "es difícil pensar que las mujeres esclavas, sobre todo las de origen africano, no hubiesen influido en la socialización de los/as niños/as de las familias mantuanas, siendo ellas como fueron las encargadas de su crianza" (p. 85). Este acercamiento afectivo y de cuidado de las ayas, amas de leche y nodrizas determinaron muchos de los va- 
lores, imaginarios sociales, tradiciones culturales y mitos que recrearon la vida y emocionalidades de los niños y niñas durante la colonia, y hoy se expresan en muchos géneros literarios como los cuentos, poesías y canciones que reflejamos en nuestra cotidianidad de herencia africana.

Por otro lado, es interesante el estudio que hace nuestro investigador afrovenezolano José Marcial Ramos Guédez en relación con cuatro nodrizas y ayas reconocidas descendientes del África. Una de ellas es Elena Cornieles, mujer parda de la ciudad de Mérida, quién amamantó a un nieto del capitán Francisco de Uzcátegui luego de la muerte de su madre doña Catalina de Uzcátegui.

La aya Socorro Gómez se encargó del cuidado y protección del general Carlos Manuel Piar durante su infancia en La Guaira. Otro caso es el de la aya negra María Josefa, esclava manumisa que se encargaba del servicio doméstico del matrimonio de origen judío entre Isaac Pardo y María de Jesús Monsanto quienes tuvieron trece hijos; los niños llamaban Pepa a su aya. Ramos Guédez (2019) recoge el siguiente relato: "La inquietud y las voces de sus numerosos hijos la hacían sufrir, y quien se ocupaba de ellos era María Josefa" (p. 60) .Y no puede faltar la negra Hipólita (1763-1835), la nodriza y aya recordada y adorada por el Libertador Simón Bolívar, a quien arrulló con sus cantos en su regazo. Esta afectividad y amor eterno es recogida en el poema de Andrés Eloy Blanco (2008) en la Reláfica de la negra Hipólita:

\author{
¿Uté ha visto?, \\ iLe va a pegá! \\ ¿Y po que le va a pegá? \\ ¿Po que e su mama? \\ Esa e rasón; \\ Yo también soy su mama; \\ Su mama somo la dó. \\ iNo me le pegue al niño, \\ Misia consesión! \\ Déjemelo maluco, \\ Déjemelo grosero, \\ Déjemelo lambío, \\ Déjemelo pegón. \\ ¿Qué les pega a los blancos?, \\ ¿Qué le pega los negros?, \\ ¿qué le pega a tós?
}


ipues, que les pegue, que les pegue,

que les rompa el morro,

que les rompa el josíco,

que tiene razón!

Mi niño no é malo,

Lo que pasa é lo que pasa, Misia cosesión:

Que defiende a los chiquitos,

a los negritos,

a los blanquitos,

contra e grandulón.

Mi niño Simón é malo,

Mi niño Simón pelea,

Mi niño Simón é el diablo,

Mi niño Simón é la incorresión de la incorresión...

iPero é que uté no sabe, é que uté no sabe

cómo hay gente mala, mi ama Consesión!

Que viene lo blanco malo,

que viene lo negro malo,

que viene lo grande malo,

iahí está el pegao!

que le brinca a la bemba,

que le brinca al guargüero,

que le brinca a la pasa

que le brinca a tó;

y tiene justicia pa pone la mano

y é la incorresión de la incorresión...

iNo me le vaya a pegá!

Uté no é más mai que yo.

Déjemelo endiablao,

Deje que pelee

Mi niño Simón...

El poema de Andrés Eloy Blanco nos deja ver el afecto que conlleva ser la madre de leche, el amor que siente por el pequeño es tal que llega a la justificación, con tonos de alcahueterías, para argumentar las andanzas y rebeldías del niño Simón. Asimismo, podemos señalar que en la historiografía venezolana y en los textos escolares se nombran a dos mujeres muy significativas en la vida del Libertador: Hipólita y Matea. Ambas mujeres fueron esclavizadas de la familia Bolívar. Sin embargo, es notorio y se hace común en el colectivo del imaginario 
popular de los y las venezolanas la tendencia a confundir a Hipólita con Matea. ¿Cuál de las dos lo crío? ¿Quién lo amamantó? ¿Ambas están estrecha y amorosamente relacionadas con la vida del Libertador?

Veamos. En relación con la negra Matea, como se le ha reconocido en la historia, es interesante citar al investigador afrovenezolano Ramos Guédez (2019), hombre acucioso que expresa:

Advertimos, que en los múltiples escritos de Simón Bolívar plasmados en cartas, discursos, proclamas, decretos y otros no hemos encontrado ninguna referencia emitida por nuestro Libertador sobre la negra Matea quien según muchos historiadores, biógrafos y aficionados a los estudios de los anales patrios, también fue aya del máximo hijo de la ciudad de Caracas. Además, algunos autores consideran que la negra Matea, aunque fue una esclavizada de la familia de Bolívar no estuvo vinculada con la crianza del niño Simón. (pp. 53-54)

Y sintetiza que esta adjudicación de aya del Libertador la identificó el general Antonio Guzmán Blanco (1829-1899) durante los actos oficiales con motivo de la celebración del Centenario del Nacimiento de Simón Bolívar en el año de 1883. En este mismo orden de ideas, el investigador venezolano José Sanz Roz (2008), el cual tiene más de veinte libros de historia publicados, señala:

aunque la negra Matea fue un personaje que realmente existió, no pudo ser nunca nodriza del padre de la patria. Bolívar jamás menciono en sus cartas y sus conversaciones a la negra Matea: aunque sí refirió varias veces a sus dos genuinas nodrizas: la dama realista Inés de Mijares y a la esclavizada negra Hipólita. Para 1883, centenario de nuestro Libertador, la negra Matea está aún viva, y subsistió tres o cuatro años más. (párr.4)

De acuerdo con los párrafos que anteceden y las expresiones de los autores antes mencionados, queremos advertir que no desestimamos a la esclavizada Matea. Se calcula que para el momento del nacimiento del niño Simón, Matea tendría entre ocho y diez años, ya que no se precisa la fecha de su nacimiento. Siendo esto así y debido a la presencia de Matea en el centenario de la muerte del padre de la patria en 1883, no pudo haber sido su nodriza o madre de leche. Pero no dudamos que sí lo cuido, estuvo a su lado, seguramente lo acobijó en sus brazos y le cantó. A medida que fueron creciendo el niño Simón y la negra Matea, también compartieron juegos y travesuras juntos, se convirtió en su aya y cuidadora, y nos atrevemos a señalar que se convirtió en una hermana y maestra.

En relación con Hipólita, dejemos que sea el verbo escrito del Libertador quien nos despeje las dudas acerca de su afinidad afectiva, espiritual y su cercanía. De acuerdo con las cartas emitidas por Bolívar el 10 de julio de 1825, cuando se encontraba en el Cuzco (Perú), se enteró de que su madre Hipólita estaba con limitaciones económicas para cubrir sus necesidades. Por ello, le escribe a su 
hermana María Antonia una carta que, sin temor a exagerar, podemos señalar como una de las más enternecedoras, donde demuestra su cercanía filial: "Te mando una carta de mi madre Hipólita, para que le des todo lo que ella quiera, para que hagas por ella como si fuera tu madre, su leche a alimentado mi vida y no he conocido otro padre que ella" (Barletta, 2011, p. 22).

Para finalizar este apartado, es interesante rescatar el relato del investigador José Marcial Ramos Guédez (2019) sobre la transcendente presencia de las ayas y nodrizas en la Venezuela colonial:

En la Venezuela colonial, observamos la presencia de mujeres negras, mulatas o zambas, sometidas a esclavitud o en situación de libertad, quienes ejercieron las funciones de nodrizas y ayas, las primeras les daban la leche de sus senos a los hijos e hijas de las mujeres blancas mantuanas y las segundas, estaban destinadas al cuidado y protección de los infantes y jóvenes nacidos en las familias aristocráticas antes mencionadas. (p. 22)

De acuerdo con lo expresado por el autor, podemos comentar que el papel que protagonizaron las esclavizadas africanas en la Venezuela colonial fue sumamente importante, pues sin el cuidado de las madres sustitutas muchos de los niños y niñas no hubiesen sentido el prodigio amor de las africanas. No dudamos de los sacrificios que muchas de estas mujeres nodrizas tuvieron que enfrentar al dejar a un lado el cuidado de sus propios hijos e hijas. Pero tampoco dudamos de todo el bagaje cultural que fue infundido; la transmisión de sus tradiciones, mitos y leyendas; y la labor de educativa y el aprendizaje que se dio al calor del abrigo, amor ternura y compromiso de sus nodrizas y ayas.

\section{Las nodrizas y amas de leche en Brasil}

Es interesante comprender la dinámica de la diáspora africana, ya que tiene elementos vinculados a la construcción de la identidad en relación con su lugar de origen. En este sentido, responde a un pasado común vinculado a la comunidad que lo acoge con una cultura nacional, lo cual los ubica en una complejidad sobre una comunidad imaginada y creada con elementos de origen (propios) y elementos de destino (ajenos).

En este caso, incorporamos el estudio de las prácticas de crianza en el Brasil como punto de encuentro y retorno de la cultura afrodescendiente porque fue el lugar de llegada del 38 \% de la diáspora africana para trabajar en las minas y plantaciones, por lo que se convierte en un espacio interesante para explorar la transmisión de la sabiduría y prácticas africanas. Al respecto, Gilroy (1993) hace un análisis de la diáspora africana, la cual se caracteriza, según este autor, por "las formas culturales estereofónicas, bilingües o bifocales originadas por los negros $[\ldots]$ y diseminadas al interior de las estructuras del sentir, producir, 
comunicar y recordar" (p. 3). De esta manera, define la construcción de una diáspora con identidad híbrida, en respuesta a los cambios y transformaciones de las diferentes comunidades que integraron la diáspora africana.

En este contexto, la tradición se convierte en el refugio y espacio de autoafirmación de la cultura africana frente a la colonización como eje para consolidar una identidad común que desarrolla mecanismos de resistencia ligadas a las experiencias, subjetividades y relaciones sociales que se derivan de la opresión vivida por la esclavitud; la tradición es la huella de la diáspora africana en la arena de la modernidad. En relación con el sujeto de la diáspora africana en cuanto su territorialidad "espacio-cultura" y retomando las ideas de Gilroy (1993), Fernández (2008) afirma: "El Atlántico simboliza el espacio de expansión y la nave el lugar de encuentro, confrontación y conflicto, de negociación e intercambio entre los distintos sujetos" (p. 314).

Desde esta perspectiva, la diáspora nace y se alimenta de la interrelación de la cultura pasada y la cultura presente, en dos espacios y en dos tiempos, donde transcienden elementos de arraigo y apego al entorno conocido como recuerdo y memoria que favorece el proceso de adaptación y reconfiguración en la exploración de nuevos horizontes.

Por tanto, en función de los elementos tradicionales de la diáspora africana que recorrió las tierras del Brasil y la influencia de los procesos ambientales encontrados, es pertinente explorar la confluencia y amalgama de los aportes culturales, religiosos y espirituales como vestigio de las nodrizas y amas de leche en el seno de las familias esclavistas en Salvador de Bahía. El investigador venezolano Jesús García (2013) hace referencia al literato brasileño Jorge Amado sobre la presencia africana en Brasil, quien expresa:

Lo que debemos proclamar en público y exhibir ante los ojos del mundo es la presencia de África en Brasil, su presencia en nuestras vidas, en nuestra cultura, en el rostro de nuestro pueblo, dándonos la medida exacta de su grandeza. Allí está el negro africano presente en todo cuanto hacemos de importancia. Allí está el África, con su sol y con su sombra, en los profetas, santos ángeles que el Aleijadhinho fue esculpiendo por los caminos del oro de Minas Gerais.

Las nodrizas y amas de leche ingresaron a las familias de la colonia portuguesa en Brasil como esclavas domésticas con la función exclusiva de amamantar y cuidar a los hijos e hijas de los eurodescendientes. En la cultura europea era común que el amamantamiento de los recién nacidos fuese ejercido por una madre distinta a la madre biológica que se encontrara amamantando a su propio hijo e hija. En Portugal, este oficio era delegado a las mujeres más pobres y en Brasil fue destinado a las amas de leche esclavizadas. Esta situación no permitía que las amas de leche esclavizadas tuviesen derecho sobre la leche 
que producía su propio cuerpo para alimentar al bebé que había procreado, por lo cual, en la mayoría de los casos, mamá e hijo eran separados inmediatamente después del parto. Por tanto, se le impedía amamantar a su hijo o hija y se le obligada a ejercer como nodriza. Las nodrizas rompían con el vínculo más profundo y estrecho que conocían en África, el de madre e hijo, aunque este perduró como símbolo de resistencia y lucha en las mujeres esclavizadas. Al respecto, la investigadora Brasilera Silva (2011) señala:

El niño podría haber fallecido o haber sido colocado en la llamada Rueda de los Expósitos. Todo niño enviado para esta institución era denominado expósito y muchas veces, fallecía antes de completar tres años de edad. Mientras tanto, para ser aceptada como nodriza, la madre era sometida a una serie de exámenes físicos y morales. (p. 9)

Sin embargo, la incorporación de nodrizas africanas permitió que se conocieran y asimilaran el tipo de relaciones maternales africanas y afrobrasileñas en las familias esclavistas, ya que desde su trabajo, su cuerpo y su vida entregaron los conocimientos africanos para nutrir física y emocionalmente a sus hijos e hijas de leche para beneficiar a los recién nacidos por el resto de sus vidas. Las nodrizas proporcionaron a las familias esclavistas prácticas de maternidad y apego despreciadas o prohibidas en la cultura europea. Al respecto, Pollak-Eltz (2000) señala:

Al mundo blanco llegaron los conceptos y prácticas africanas a través de las nodrizas de color, que transmitían a los niños blancos de sus amos creencias, supersticiones, leyendas ancestrales, métodos para invocar a las potencias sobrenaturales y conocimientos de la medicina tradicional. (p. 98)

\section{Balanceo, porteo, cuentos, canciones y arrullos: legado ancestral de nuestras nodrizas, ayas y madres de leche}

Una práctica de crianza que estableció lazos de pertenencia y cariño frente a sus amas de leche fue el vínculo mientras los llevaban en sus espaldas (porteo) durante todo el día para realizar sus labores, tanto despiertos como dormidos. Los bebés escuchaban nanas ${ }^{1}$, tarareos, cuentos, canciones, leyendas y mitos pertenecientes al otro lado del mundo: el África. En el diario de Sir Ker Porter entre los años 1825 y 1832, cuando era cónsul británico en Venezuela, se describe: "las maneras de cargar a los /as niños/as (de clara influencia indígena-africana), la desnudez de estos hasta los cuatro años (andar en aboriginal nature)" (citado por Vargas-Arenas, 2019, p. 86).

También conocidas como canciones de cuna que, desde su ritmo tranquilo y suave. ayuda a los bebés a relajarse, sentirse seguros y conciliar el sueño con la voz de sus madres, nodrizas y ayas. 
Esta afectividad desde el apego corporal estimuló un desarrollo cognitivo y psicomotor más acelerado como legado africano; las niñas y los niños eran más independientes, con mayor confianza y destreza intelectual. En las siguientes imágenes (figuras 1, 2, 3 y 4) se refleja el porteo del bebé por parte de una ama de leche en Brasil (Bahía), donde se visualiza la libertad, seguridad y relajación del bebé mientras la madre se dispone a realizar sus tareas domésticas, lo cual produce un sentido de confianza e intimidad del bebe con su madre de leche.
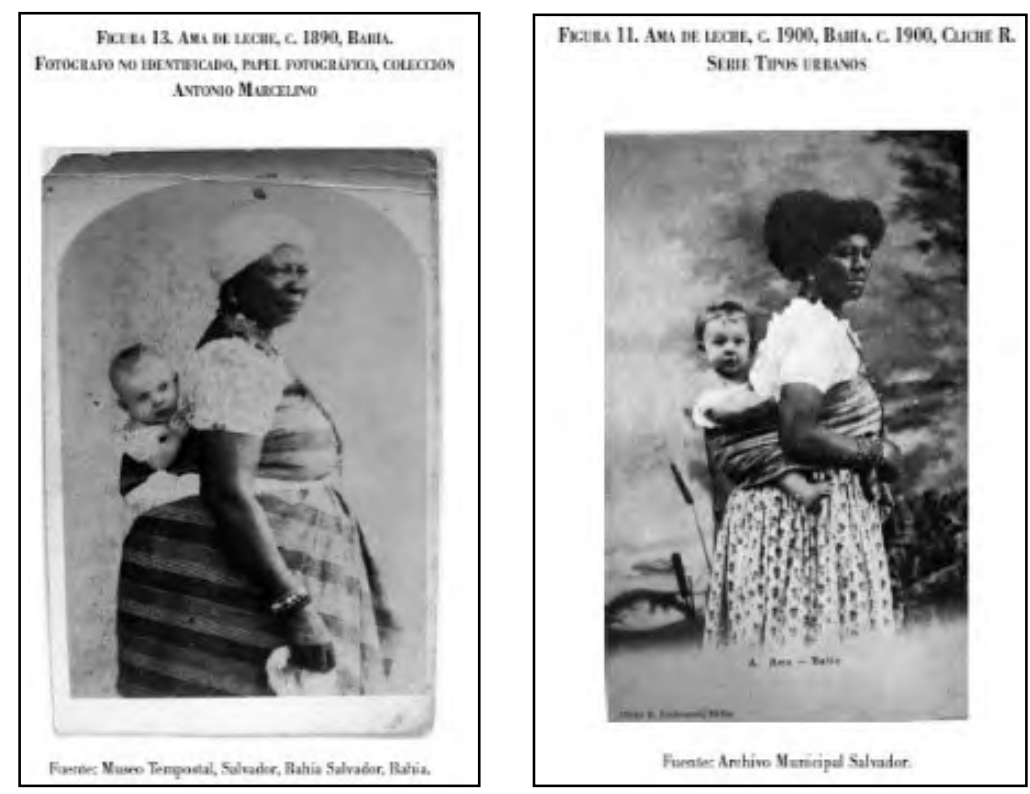

Figuras 1 y 2 . Porteo de niños y niñas.

Fuente: Silva (2011, pp. 134 y 133).

De allí que la cultura maternal africana aflorara en la vida y crianza de los niños y niñas en el Brasil desde la costumbre de amamantar a sus hijos e hijas y mantenerlos atados a su espalda, de manera que madre e hijo formaran un solo cuerpo para afianzar el aprendizaje del lenguaje y la cultura a través de los cantos, arrullos, cuentos y poesías en armonía con las labores y el trabajo en constante interacción de madre e hijo. Así lo expresa Pollak-Eltz (2000): "Las nodrizas contaban los cuentos de Tío Tigre y Tío Conejo a los niños de la burguesía. Las abuelas negras recordaban las narraciones tradicionales africanas" (p. 98). Estas prácticas de crianza representan un retorno del África a nuestra Abya Yala y el Caribe, donde las africanas y afrodescendientes están con las niñas y niños enlazados a sus cuerpos o junto a ellas; el bebe se vuelve una extensión del propio cuerpo de la madre. Mientras ejercen sus oficios de trabajo, les narran cuentos y leyendas africanas. 

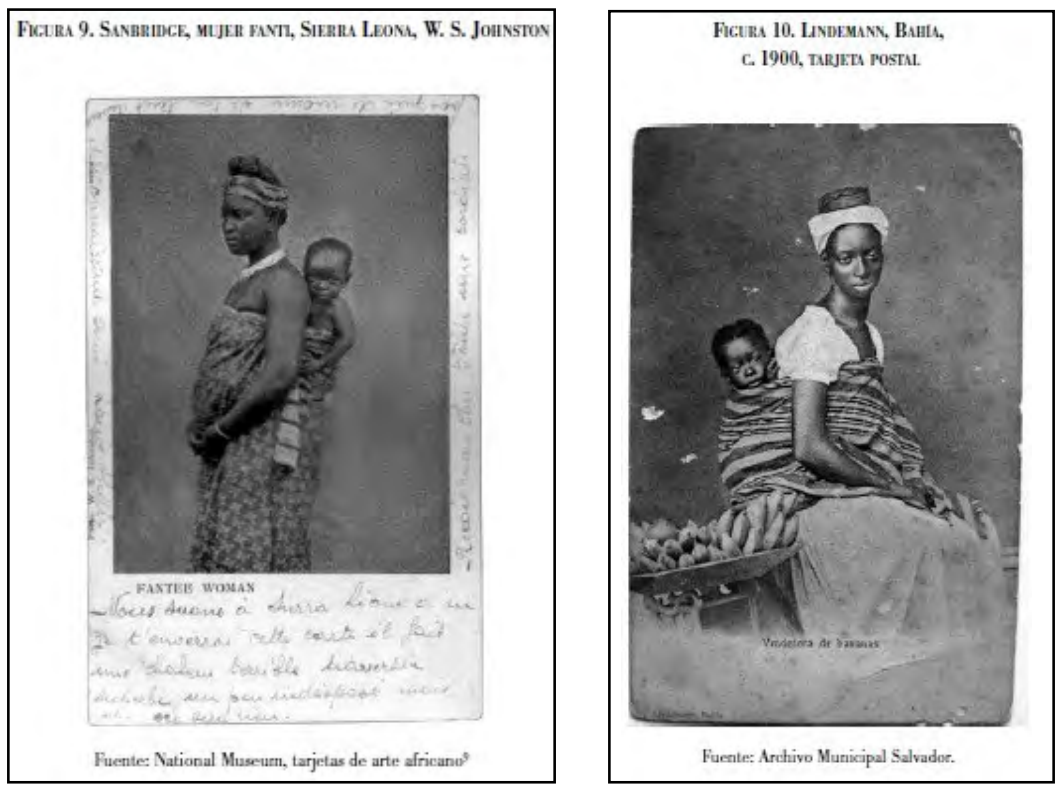

Figuras 3 y 4.Mujer africana fanti y afrobrasileña. Porteo del niño

Fuente: Silva (2011, pp. 132 y 133).

Por tanto, una de las prácticas de crianza aportadas por las mujeres africanas es el modo de cargar a los recién nacidos, costumbre ampliamente difundida en África ${ }^{2}$ para la transmisión de profundos valores africanos a través del contacto permanente con el calor humano de la madre. Como bien lo señala Silva (2011):

Uno de los beneficios aportados por las nodrizas africanas y afrodescendientes derivó del modo de cargar los recién nacidos atados a la espalda, trasmitiendo así profundos conocimientos africanos. Este método beneficia al niño por el contacto con el calor del cuerpo humano (Charpak, 2006); además, la cabeza permanece libre, mientras las piernas en $\mathrm{M}$ y las rodillas más elevadas que la cadera, permiten el desarrollo correcto y estable de la columna (p. 20)

Las madres africanas y nodrizas, al elevar a sus hijas e hijos atados a sus espaldas y amarrado en su manto, ofrecen al bebé una posición de comodidad y bienestar que les permite dormirse profundamente con la cabeza balanceando de un lado a otro, y cuando están despiertos permanecen tarareando o palmeando la espalda de su madre; mantienen un diálogo permanente con ella, al que responden con un lenguaje común y universal de los bebés ${ }^{3}$. Este método de cargar a las niñas y niños permite la libertad de movimiento de los

\footnotetext{
2 África Occidental, de donde procedían las personas enviadas a Bahía en el último período del tráfico transatlántico.

3 Estas prácticas muy bien pueden ser apreciadas en las figuras $\mathrm{N}^{\circ} 3$ y 4. 
brazos de la madre y su tranquilidad para desarrollar sus actividades cotidianas, aunque en muchas ocasiones lo que transporta es naturalmente cargado en la cabeza. Mientras el bebé crece, la posición de acogerlo cambia y empiezan a ser cargados de lado. Esta posición también es usada para favorecer el proceso de amamantamiento y la instauración del apego entre la ama de leche y el bebé. "Los niños blancos son a veces alzados de esta manera por sus criadas, y es extraordinario ver cómo se encariñan rápidamente de las negras que parecen tener una verdadera aptitud para cuidar niños" (Silva, 2011, p. 22).

En Salvador de Bahía, la más africana de las provincias de Brasil, se hace visible el valor a la maternidad afro y los procesos de asimilación de las prácticas de crianza de la cultura africana a través de las amas de leche y nodrizas, portadoras de conocimientos que garantizaban el desarrollo saludable de los recién nacidos desde saberes espirituales, medicinales, curativos y culinarios.

Christianne Silva (2011) señala que en 1904 un artículo de la Gaceta Médica de Bahía hacía referencia a la leche materna y comparaba a las mujeres africanas con las mujeres europeas:

La alta cantidad de aceite que abunda la membrana adiposa, sirve para cambiar la acrimonia de los líquidos en los países calientes, de donde son naturales, volviéndose más dulce la leche de las negras de toda la costa de África y por eso más propicio para la nutrición de los infantes. (p. 5)

Las nodrizas entregaron a sus hijas e hijos de leche los beneficios de su compañía, que disfrutaban día a día los recién nacidos, prendados y hechizados con el pensamiento mágico-religioso, mitos y leyendas originarias del continente africano. Desde el amor, sembraron las expresiones culturales del África y el arrullo de las ideas de libertad e igualdad entre todos los seres humanos en América y el Caribe.

Como bien lo expresa Pollak-Eltz (2000): "las nodrizas jugaban un rol social de suma importancia en la formación de los niños de la clase alta. Eran personas de gran confianza y sus relaciones con sus ahijados eran más estrechas que con su misma prole" (p. 113).

La misma autora afirma cómo celebran la cofradía del Santísimo Sacramento del Altar en la costa de Aragua en el pueblo de Chuao con "los bailes de diablos, que llevan máscaras que recuerdan a las que usan los Bapende del Congo en sus ceremonias" (p. 35).

Por otro lado, en su trabajo Mujeres de origen africano en la capital novohispana siglos XVII y XVIII, Velázquez (2006) afirma que existe influencia de ritmos y cantos de origen africano en la música mexicana y en especial en las canciones 
infantiles, como experiencia del vínculo entre las nodrizas y los niños. Una de estas canciones es Acitrón de un fandango que tiene su origen en la época colonial y recrea una canción de juego con palabras de origen bantú, transmitida por las mujeres africanas a los niños y niñas en México:

\author{
Acitrón de un fandango, \\ sango sango sabaré, \\ sabaré de barandela \\ con su triqui-triqui-trán. (citado en Velázquez, 2006, p. 190)
}

En este mismo trabajo se retoman versos de sor Juana Inés de la Cruz que nos cuentan sobre la presencia de las mujeres de origen africano como amas de leche. A continuación, se relaciona una estrofa de un villancico dedicado a la Asunción de 1685:

$$
\begin{gathered}
\text { iOh Santa María, } \\
\text { que a dios parió } \\
\text { sin haber comadre } \\
\text { ni tené doló! } \\
\text { iRorro, rorro, rorro, } \\
\text { Rorro, rorro, ro! }
\end{gathered}
$$

iQué cuaja, qué cuaja, qué cuaja,

que cuajá te doy!...(citado en Velázquez, 2006, pp. 190-191)

De igual manera, los cuentos representaban una práctica de crianza instaurada por las nodrizas y ayas africanas mientras compartían e intercambiaban con sus hijos e hijas de leche. Las narraciones acompañaban el acto de amamantar y cuidado con la intención de recrear sus vivencias del África y mostrar los valores de la vida del mundo africano anhelado, extrañado, recordado que hoy persisten en nuestra cotidianidad como legado ancestral. Acosta (1984) lo reafirma:

Los cuentos de Tío Tigre y Tío Conejo, que no han sido sino la prolongación de narraciones africanas en América, llegaron hasta nuestros días de labio en labio de esclavas; de memoria en memoria de manumisas; de recuerdo en recuerdo de mamas negras; de campo en campo y de ciudad en ciudad. Los viejos cuentos educativos y explicativos de la vida del mundo africano pasaron el océano y tomaron entre nosotros las encarnaciones de Tío Conejo y Tío Tigre. (p. 205)

Además, el investigador afrovenezolano Jesús "Chucho" García (1997) nos explica que los valores están siempre presentes en los cuentos heredados del África desde la tradición oral y nos ayudan a combatir el egoísmo y la avaricia para encontrarnos con el respeto, el amor, la paciencia, el trabajo y el valor de la palabra.

El autor nos narra su experiencia: "las abuelas nos insistían permanentemente [...] no hay que ser agayuo [sic] en la vida mi hijo, hay que arroparse 
hasta que donde la cobija alcance" (García, 1997, p. 65). Este principio se refleja en los cuentos La mata de maní, Musiurrutan, En la Virgen de Caño Méndez que aprendió de su abuela materna Trina García: "En esos cuentos que resisten aún hoy, [...] podemos encontrar una génesis de nuestra idiosincrasia, de nuestro pensamiento actual" (García, 1997, p. 24). Y así nos relata el cuento El venado y el morrocoy:

Cierta vez, el venado observando el lento caminar del morrocoy, comenzó a reírse. Esto molestó mucho al morrocoy, quien interpelándolo le dijo:

-Te burlas, porque me vez caminar más lento que tú. Pero te aseguro que si hacemos una apuesta, a la hora y día que tú quieras te gano la carrera.

El venado se destornilló de risa, escuchando las pretensiones del morrocoy. Mas, fue tanta la insistencia de éste, que el venado aceptó la apuesta.

Llegó el día fijado para la carrera. Todos los animales fueron invitados a presenciarla. Ya el morrocoy había apostado otros morrocoyes a lo largo del trayecto que habrían de seguir.

Cachicamo dio la voz de partida. El venado dio dos saltos y se perdió de vista.

Considerando que el pobre conchudo ya había perdido gritó: -iiMorrocoy, coy, coy!!

Y su sorpresa fue grande, cuando delante de él le respondieron: —iAlance voy!...

Nueva carrera a través de la selva. Se sentía cansón. Gritó de nuevo:

-iMorrocoy, coy, coy! - Volvieron a responderle como a dos tiros de escopeta delante de él.

Desesperado, sacó el resto de fuerzas que le quedaba, dejó muchas leguas atrás y, jadeante, exclamó tímidamente:

-iMorrocoy, coy, coy!...

iAlante voy!...-le respondieron, siempre delante de él.

El venado ya no podía resistir más el cansancio, y cuando llegó a la meta, encontró muy campante al morrocoy, que le esperaba riendo. (García, 1997,pp. 64-65)

\section{Al cuidado y abrigo de las ayas y nodrizas: madres de leche y de crianza afrovenezolanas}

$Y$ bendito sea el fruto de tu vientre: Jesús. Este fragmento del rezo del avemaría, vestigio del adoctrinamiento infundido por la iglesia católica desde tiempos de la colonia, es una huella indeleble del rol que asume la mujer como dadora de vida y continuidad de la humanidad. Su vientre es el primer abrigo, en el vientre materno crece y se reproduce un nuevo ser: el fruto, por eso su vientre es bendito recreado en esta frase y realidad. Las mujeres en la colonia, las mantuanas, fueron sus vientres, el fruto de sus hijos. Pero su cuerpo, en muchos casos, solo 
fue para la reproducción, pues recurrieron a esclavizadas africanas que fueron llamadas mamás de crianza, mamás de cría, mamás de leche, criandera o nodriza. El hecho tan hermoso de recostar a sus pequeños en su regazo y su abrigo se le concedió a las africanas, las cuales ocuparon el lugar de madre biológica amantando a sus hijos/as esclavizadas que cumplían las labores domésticas, entre otros menesteres propios del cuidado y limpieza de la casa. Esta práctica fue muy común en el siglo XIX.

En el testimonio que Miguel Machado (hijo de Rosa Machado de García) nos cuenta sobre su bisabuela Guillermina Aponte ${ }^{4}$, se revela el papel otorgado a las esclavizadas negras en cuanto al cuidado de los niños, niñas y las interminables tareas domésticas. En la Venezuela colonial hubo un gran predominio de mujeres africanas esclavizadas que se dedicaron en muchas ciudades al servicio doméstico, especialmente en Caracas, Mérida, Coro, Maracaibo, Barquisimeto, Cumana, San Felipe, Valencia, Maracay, San Carlos, Barcelona, San Sebastián de los Reyes y Angostura (actual ciudad Bolívar).

Es importante resaltar el papel fundamental que estas mujeres esclavizadas ejercieron en la fundación de nuevos espacios luego de conseguir su libertad. Tal es el caso de la señora Guillermina, la cual debe su apellido al lugar del cual llegó "De Aponte" (asumimos que el nombre de la hacienda) a las costas del pueblo de Choroní. Deseamos destacar que hoy día sus herederos conservan el apellido Aponte, pues la señora Guillermina estableció la fundación de este pueblo afroaragüeño y, según la tradición oral, "[l]a mujer fue la que trajo la riqueza a Choroní". A continuación, relacionamos extractos de la entrevista realizada:

Investigadora: ¿De dónde viene Guillermina?

Miguel Machado: Y era, eran cosas de aquella época... y bueno, desde que tengo uso de razón, según mis abuelos... Guillermina viene del pueblo De Aponte, lo que se llama ahora Costa de Oro en la región de Ocumare, en una serranía de una hacienda que eran haciendas de esclavos. Guillermina era como la cunadora (cuidadora) de los niños de los dueños de esa hacienda y ellos la trataron muy bien y le dieron una cantidad importante de dinero y se vino con su hija Rosa Aponte, que era mi abuela, ya en brazos para acá en Choroní. Y a aquí, bueno, se puso a inventar vaina, porque con su (cómo se llama eso), su bastimento, como decían antes, esa era una paca que envolvían en periódico como con cabuya y vaina. Pero los billetes valían en aquella época y conoció a Genaro Medina, y creo que quiso administrarle la pequeña fortuna que ella tenía para hacerla progresar y eso. Era una mujer muy hacendosa según mi mamá, desde que se levantaba hasta que se acostaba. Se murió joven por eso, porque le dio como un pasmo, una cosa así; era frente a un fogón todo el día haciendo ventas, todas esas cosas que antes se hacían

Guillermina Aponte llegó a Choroní con su hermana Claudia Aponte, provenientes de una hacienda de cacao de Ocumare de la Costa, y con su hija Rosa Aponte. Era esclavizada en Ocumare y por alguna razón llega a Choroní con mucho dinero e inicia el comercio en el pueblo. 
sabrosas: arepitas dulces, arepitas dulces, arepas de maíz... y muchas cosas bien importantes. Se levantaba a las cuatro de la mañana y a las ocho de la noche por supuesto estaba vencía [sic] de todo el trabajón [sic], buscar leña. No había gas y ellas tenían mucha sabiduría en esas cosas, pues, porque no todo el mundo es talentoso para esas..., hay gente que es más talentosas con las manos para hacer bambú, artesanía, pero ellas eran la cocina, pues tenían un sazón impresionante. (Miguel Machado, comunicación personal, 23 de junio de 2019)

Este testimonio de Miguel Machado, hombre pescador oriundo del enclave afrodescendiente de Choroní, bisnieto de Guillermina, deja ver claramente la importancia de la oralidad como recurso trasmisor de historia familiar, que se ha mantenido en los miembros de la familia. Interesante que un bisnieto de Guillermina nos pueda narrar el hacer de su bisabuela en la hacienda De Aponte.

Por otro lado, es interesante traer y contextualizar los aportes del investigador afrovenezolano Ramos Guédez (2019) en su libro Africanía en Venezuela: esclavizados abolición y aportes culturales. Este libro nos acerca a la historia del proceso de transculturación e interculturalidad acontecido en la época de la colonia y que aún perdura en nuestros días, pues son las abuelas, tías, comadres, amigas, vecinas, entre otras, quienes cumplen ese rol amantar (nodrizas) y criar (ayas) a los niños y niñas venezolanos. Así, el historiador Ramos Guédez (2019) expresa:

Las ayas y nodrizas negras, zambas y mulatas, intervinieron en el proceso de transculturación e interculturalidad que aconteció en la Venezuela colonial y sus supervivencias en nuestra época contemporánea [...] sin omitir sus múltiples enseñanzas en torno a las ideas de libertad e igualdad entre todos los seres humanos. (p. 40)

En este sentido, la historia de las nodrizas y las ayas marcan un antes y un después en la sociedad venezolana, pues las mujeres esclavizadas cumplieron este rol tan importante. Acosta (2002) nos revela:

mientras la madre achacosa, remilgada, o deseosa de conservar los dones de la juventud, encargaba a la criadora el amamantamiento del hijo; éste [sic] llegaba a ver en su 'mama negra' como todavía hace pocos años se decía en Venezuela, a su verdadera mamá, a su efectiva madre. (p. 59)

Pollak-Eltz (2000) nos recuerda: "El diablo fue identificado como Mandinga. Se conservan creencias en La Llorona, la Mula Maniá y otros espíritus de posible procedencia africana" (2000, p. 98). La crianza y amamantamiento se mantiene en la Venezuela de hoy.

Las narrativas nos permitieron hacer énfasis en la comprensión de las mujeres desde su historia-vivencial, reflexionar sobre su vida y explicarlo a los demás. 
$\mathrm{Al}$ respecto hemos recopilado testimonios de mujeres que nos narran sus experiencias. Vale la pena acotar que no solo se trata de que las narradoras nos cuenten parte de su vida, sino que al mostrarlas le encuentran sentido a su experiencia y a su vida: "en la investigación narrativa, se trata de vivir la historia, donde las dos narrativas" (investigadora y protagonista) convergen en la construcción de la narración compartida (Bolívar, 2012, p. 5).

De esta manera, a continuación compartimos los emotivos, sensibles y sublimes testimonios de mujeres afrovenezolanas que cultivaron vida en hijos ajenos e hijas ajenas, pero en la memoria y en el recuerdo se convirtieron en propios:

Investigadora: ¿Has vivido la experiencia de ser madre de leche?

Lucidia Rojas (setenta y tres años): Sí, yo he sido madre de leche, yo mis tres hijos no los parí, sino que los tuve por cesárea. Cuando yo estaba cesareada [sic] de mi primer hijo lo llevan al reten de niños, en el seguro social. Y ahí como yo estaba cesareada [sic], no podía levantarme a ver a mi muchachito y darle pecho menos, entonces en el cuarto las demás parturientas que estaban conmigo que tenían sus bebes, que sí se lo daban y ellas, no tenían leche o no les bajaba la leche a sus tetas para amamantar a sus niños. En cambio a mí se me botaba la leche, yo tenía mucha leche en abundancia, me daba fiebre y yo tenía que bajar esa presión de leche y sanar para que me pudieran dar de alta. Entonces me los traían las mismas madres y las enfermeras, y yo me los pegaban en mi teta, y si eran hembras más ligero porque mis hijos fueron varones... cuando nacía mi bebe y era varón yo le regalaba a la niñita que yo amantaba de primero la ropita de hembra... Soy madre de tres niñas que hoy son mujeres y tienen la misma edad de mis hijos, mis tres tesoros que yo no las conozco, pero son también mis hijas. Pero Dios sí sabe quiénes son y a donde están. Ellas tienen la misma edad, ajá, esas son mis hijas de leche, con la misma edad. El mayor de mis hijos tiene cuarenta y nueve años, el segundo va a cumplir cuarenta y tres años y el menor que va a cumplir ahora cuarenta años. (Lucidia Rojas, comunicación personal, 19 de junio de 2019)

Investigadora: ¿Qué significado tiene para ti ser madre de leche de hijos que no has parido?

Xiomara Vargas (cincuenta y dos años): Para mí ha sido y será siempre una experiencia muy amorosa y muy tierna y de lo que me siento muy orgullosa. Cuando tuve mi primera hija, yo tenía veintidós años. Yo parí en el Victorino Santaella de los Teques y, en el momento que llega mi familia y el padre de mi hija, yo estaba amamantando a un varón, pero yo parí fue hembra. Ellos se emocionaron con el niño, yo me río y les digo este no es mi hijo, es un varón, yo tuve fue una niña. Ellos no me creyeron al momento. Yo me sentí muy feliz al tenerlo entre mis brazos a pesar de no ser mi hijo, fui su madre por momentos... A pesar de ser primeriza, yo fui muy lechera (risas), y a la mamá del bebé no le bajaba la leche, ella se lo pegaba y nada. El bebé lloraba y lloraba. Ante eso, le pedí que me lo entregara. Confieso que la madre estaba muy temerosa, pero yo insistí y me lo dio. 
Investigadora: ¿En alguna oportunidad has sido madre cuidadora de algún sobrino o sobrina, o has sido abuela al cuidado de un nieto o nieta?

Xiomara Vargas: Abuela no soy todavía, pero sí he sido madre sustituta, la tía que cría, la tía nodriza, la madre de leche. Te voy a contar otra experiencia, yo tengo una hija que el 29 de diciembre cumple treinta años. Ella me dice mamá, es mi sobrina política. Yo también la amamanté, pero a escondida de su madre. Ella, mi cuñada, era una mujer mayor, era una mujer enchapada a la antigua (risas). No le gustaba salir en las tardes por el sereno, se ponía un pañuelo en la cabeza, no comía chucherías, es decir, ella se cuidaba y cuidaba mucho a la niña. Yo mucho más joven comía chucherías, pero ella no tenía leche en abundancia, en cambio yo sí tenía. Mi suegra fue cómplice porque cuando ella se iba a trabajar, ella me daba la niña para que le diera teta. Durante aproximadamente tres meses estuve amamantando, hoy en día está en otro país. Sabes, la niña al nacer tuvo problemas bajo peso, porque su mami tenía edad avanzada al nacer, su mamá ya murió. Hoy día es una mujer muy bella, ella siempre dice que fue por mi leche que es tan hermosa.

He sido madre cuidadora, la aya, como se le decía en la colonia. Desde la edad de ocho años yo he estado al cuidado de mis hermanos. Soy la única hembra, mi madre se separó de mi padre y luego tuvo otra pareja que nos crio a todos. Le parió tres hijos, yo crie a mis tres hermanos. El primero, yo tenía apenas tenía ocho años; luego a los diez nació el otro y el tercero cuando yo tenía dieciséis años. He sido su madre. Siempre me han gustado los niños, jugaba con ellos, los atendía desde cambiar sus pañales, alimentar y le enseñé sus primeras letras. Los he cuidado como mis hijos. (Xiomara Vargas, comunicación personal, 8 de noviembre de 2019)

En el testimonio de la madre leche se promueven varios elementos para la reflexión: la madre de leche no debe haber parido para amamantar, los hijos e hijas que han bebido la leche de sus tetas también los atesora como si los hubiese mantenido en el regazo de su vientre y parido. Los lazos afectivos permanecen en el recuerdo a pesar de la distancia.

Esta visión es compartida por la experiencia propia. Nuestros relatos y testimonios forman parte de lo que ha significado en nuestras vidas el ser madres de vientre y de leche como decisión propia, a diferencia de nuestras ayas y nodrizas de la colonia que daban en sacrificio a sus propios hijos e hijas para ejercer este acto en condiciones de explotación. Pero aún en el dolor, engendraron amor, dulzura, afecto y enseñanzas en sus cuentos, leyendas, creencias y valores, regando en nuestras tierras hijos e hijas de la leche del África para parir la libertad. Compartimos nuestras narrativas de vida...

Ismenia Mercerón: Hermana el tema me mueve mucho como mujer y madre es maravilloso todo lo que acontece al tener entre nuestro cuerpo el calor de nuestros hijos, amamantar es el acto de vida más hermoso y generador de vida que podamos hacer... Amamantar es trasmitir todos nuestros afectos la leche que emana de nosotras tiene toda nuestra carga de amor que mujer alguna puede dar. (Testimonio personal, 8 de julio de 2019) 
Me encanta, ese sentir de mujer, de haber dado leche a mis hijos, de haber amamantado a mis sobrinos y niños que ni siquiera llegué a conocer [...] cuando fui madre de leche de niños, cuando parí a Jesús Armando, cuando parí a Elizabeth y me pegaron dos, tres niños, ya no recuerdo cuantos en una noche, porque las madres no tenían leche. Son mis hijos de leche que están en el mundo, y donde quiera que estén que dios me los guarde y nuestras ancestras lo protejan. (Testimonio personal, 15 de noviembre de 2019)

Diónys Rivas Armas: En principio, el acto de amamantar como tal, de nutrir la vida de tu hijo, de tu hija, desde la leche que emana tu seno, lo considero un acto de vida y un acto de amor, un acto que te va a conectar toda la vida con esa criatura que permaneció en tu vientre y bueno es dulzura, es ternura, es amor incondicional y cuando llega el momento del destete, sientes como que te están quitando algo de ti y esa misma experiencia se traslada cuando, eh, otros niños, otras niñas también se alimentan de tu pecho, de tu leche.

Mi experiencia particular fue con mi sobrina, que es contemporánea con mi hija. Actualmente tiene trece años y mi sobrina tiene doce años y por el mismo hecho de ser contemporáneas, eh, yo me reunía mucho con mi hermana, mi hermana conmigo $\mathrm{y}$, eh, mi hermana no tuvo como ese acto de amamantar muy arraigado, a diferencia de mí, que si era como algo más fuerte, algo más profundo y amamanté a mi sobrina en varias oportunidades que estuvo en mi casa. De hecho amamanté a mi sobrina y a mi hija al mismo tiempo. Y es un hijo de la vida, es un hijo que no es de tu vientre, pero que sientes que tiene parte de ti y que tú lo alimentaste. Entonces bueno en muchas oportunidades viví esa experiencia, de nutrir la vida de mi sobrina. Ver mi sobrina es ver, ver una hija más, es algo que permanece en el tiempo y que siempre recuerdas, ese momento siempre está como en tu mente. Nunca le he preguntado a ella, sí, bueno era muy pequeña, pero me gustaría en algún momento conversarlo con ella, como siempre intercambiamos, tuvimos juntas, ... lo vi algo también tan natural, se convirtió como más que en una sobrina, una hija natural y bueno te cuento que ahorita es una conexión muy bonita que tengo con mi sobrina y ella con mi hija, ... además son muy parecidas de carácter, no es que lo esté vinculando directamente a que ellas han sido alimentadas con la misma leche, pero hay un carisma que nos envuelve a mi sobrina, a mi hija y a mí. Y entonces creo que es un legado, cuando estudiamos a las comunidades afro, a las comunidades indígenas, es un legado que permanece en el tiempo y que uno lo reproduce y la vida te da esa oportunidad de tener hijos, hijos de leche y ser nodriza, como se llamaban en la colonia, esa es parte de mi experiencia. (Testimonio personal, 5 de noviembre de 2019)

\section{Algunas reflexiones finales}

Las mujeres negras esclavizadas cumplieron un rol fundamental en la reproducción de las prácticas de crianza, valores culturales y la estructuración de un imaginario colectivo de herencia africana en el continente americano y el Caribe como acto de resistencia y cimarronaje frente al proceso de esclavización y colonización. Sin embargo, estas mujeres sufrieron la privación de estructurar de manera autónoma e independiente sus propias vidas y espacio familiar para ofrecer libremente a sus propios hijos e hijas de vientre su legado ancestral y 
entregar a su descendencia elementos sociales y culturales de sus raíces familiares y su territorio.

Bien sabemos, como se desataron las uniones forzadas entre esclavizadas y europeos, que tenían dos objetivos fundamentales para el control de los cuerpos racializados de las africanas: el placer, goce y disfrute de los amos y la reproducción de nuevos esclavos y esclavas para aumentar la producción, riqueza y fuerza de trabajo en las plantaciones sin necesidad de recurrir a la trata negrera. Frente a esta degradante práctica colonizadora, las mujeres optaban por controlar su propia fertilidad a través del uso de plantas, pociones, el aborto, entrega o abandono de sus hijos e hijas. Recordamos un relato de Tituba que ilustra esta idea fielmente, narra nuestra Bruja negra de Salem:

Para una esclava, la maternidad no es una dicha. Equivale a expeler hacia un mundo de servidumbre y adyección a un pequeño inocente cuyo destino le será imposible cambiar. Durante mi infancia había visto a esclavas asesinar a su recién nacido clavando una larga espina en el huevo aún gelatinoso de sus cabecitas, o cortando el cordón umbilical con un cuchillo untado de veneno, o también abandonándolos de noche en algún lugar frecuentado por espíritus irritados. (Condé, 2014, pp. 65-66)

En este sentido, es interesante indagar sobre investigaciones y estudios que nos permitan disponer de información de cómo fue el proceso de transmisión de valores y creencias de las mujeres africanas a sus propios hijos e hijas de vientre cuando las esclavizadas tenían la posibilidad de convivir con ellos mientras se dedicaban al servicio doméstico o a las actividades agrícolas.

Además, se hace necesario conocer cómo fue la convivencia familiar en los cumbes, cómo se establecían las uniones de parejas y los acuerdos en cuanto al cuidado y crianza de sus hijos e hijas, considerando la diversidad de civilizaciones que confluían en estos espacios libertarios, pues en muchos de ellos se practicaba la poligamia ancestral africana. Según los estudios de Vargas-Arenas (2019), en muchos de los cumbes jamaiquinos: "la poligamia fue prerrogativa de los esclavos fugitivos más importantes, lo que regulaba aún más la posesión femenina y el control sobre las mujeres y su sexualidad" (p. 138).

Por otro lado, es importante reflexionar sobre los procesos de transculturación que se gestaron, donde diferentes rasgos pasaron a conformar la cultura en Venezuela a través de préstamos culturales, traslados, influencias y relaciones que propiciaron la creación de un mosaico cultural para la subsistencia y resistencia de los europeos, indígenas y africanos en nuestro país. Acosta (2014b) insiste en el fundamental papel de las y los africanos en los procesos de transculturación: "fueron ellos quienes en diversas ocasiones sembraron elementos culturales y en otras oportunidades [...] fueron los conservadores de los antiguos procedimientos indígenas" (p. 323). 
Para finalizar, es importante precisar que, ciertamente, las mujeres africanas como nodrizas y ayas no lograron el disfrute pleno y decisivo de su maternidad, sufrieron la expoliación de sus cuerpos y de lo que emanaba de él: su leche, su sudor, su sangre, sus fluidos se convirtieron en vientre de dolor, vientre de sangre. Pero se convirtieron en vientre de amor vertiendo su esencia en los hijos e hijas de leche que regaron en suelo venezolano.

Aún en sus condiciones y dificultades, no silenciaron sus vivencias, sus palabras, arrullos, canciones y poesías que todavía persisten en nuestras prácticas y memoria ancestral. Se convirtieron en la compasión de su alma y espíritu ante la ausencia del regocijo, del resguardo de la tierra propia, del sentir y el deseo para la resistencia y re-existencia de ser madres con pezones y vientre de libertad. Cerramos estas reflexiones con el poema La despedida de la nodriza africana (Rodríguez, 1848, citado en González, 1992, pp. 169-171), que representa un testimonio vivo y grito de una nodriza africana:

\title{
La despedida de la nodriza africana
}

\author{
Cuando tus nítidos labios, \\ ángel hermoso, bebían \\ la sustancia que vertían \\ etíopes pechos de amor, \\ yo feliz te contemplaba \\ y sobre tan tersa frente \\ aun más de un beso inocente \\ mi boca humilde imprimió \\ [...] \\ Así sereno dormías \\ el sueño de la inocencia, \\ mientras que a la Omnipotencia \\ plácida alababa yo; \\ pues por influjo benigno \\ de sus secretos arcanos, \\ trájome a climas lejanos \\ a ser tu madre de amor \\ [...] \\ Y allá en tus sueños floridos, \\ cuando su embeleso seas \\ y sus cariños poseas \\ no olvides ioh, niño!, no, \\ que sobre mi pecho un día \\ probaste en muy dulces calmas, \\ que hay también sensibles almas \\ en donde es ingrato el sol.
}




\section{Referencias}

Acosta, M. (1984). Vida de los esclavos negros en Venezuela. Vadell hermanos Editores.

Acosta, M. (2002). Dialéctica del Libertador: Introducción, recopilación y notas de Ramón Losada Aldana. Universidad Central de Venezuela, Ediciones de la Biblioteca.

Acosta, M. (2014a). Estudios para la formación de nuestra identidad. Fundación Editorial el Perro y la Rana.

Acosta, M. (2014b). Estudios de etnología antigua de Venezuela. Centro Nacional de Historia.

Alvárez, M. (2010). Historia de lucha de la mujer venezolana. Fundación Editorial el Perro y la Rana.

Barletta, R. (2011). Breve Historia de Simón Bolívar. Ediciones Nowtilus.

Bolívar, A. (2012) Metodología de la investigación biográfico-narrativa: Recogida y análisis de datos. En M. C. Passegi y M. H. Abrahao (orgs.), Dimensões epistemológicas e metodológicas da investigação (auto)biográfica. Tomo II (pp. 79-109). Editoria da PUCRS. https://doi.org/10.13140/rg.2.1.2200.3929

Bolívar A, Segovia D, y Fernández C, M. (2001). La investigación biográfico-narrativa en educación. Enfoque y metodología. Muralla.

Blanco, A. (2008). Píntame Angelitos Negros. Para Colorear. Fundación Editorial el Perro y la Rana. Colección Caminos del Sur.

Cardona, M. y Terán, V. (2017). Pautas, prácticas y creencias de crianza de las familiasafrodescendientescordobesas. Eleuthera, 17, 13-30. http://190.15.17.25/eleuthera/downloads/Eleuthera17_2.pdf

Carrera, D. (1993). Simón Bolívar Fundamental. Volumen 1. Monte Ávila Editores Latinoamericana.

Condé, M. (2014). Yo, Tituba, bruja negra de Salem. Edición de Monte Ávila Editores Latinoamericana.

Duno-Gottberg, L. (2014). La Humanidad como mercancía: introducción a la esclavitud en América y el Caribe. Fundación Centro de Estudios Latinoamericanos Rómulo Gallegos.

Fernández M. (2008). Diáspora: la complejidad de un término.Revista Venezolana de Análisis de Coyuntura, 14(2), 305-326. http://190.169.94.12/ojs/index.php/rev_ac/article/view/10580

García, J. (2013). En Brasil, el ombligo es la referencia de la vida. El Mercurio Digital. https://elmercuriodigitalpuntoes.wordpress.com/2013/04/30/en-brasil-el-ombligo-es-la-referencia-de-la-vida/

García, J. (1997). Barloventeñidad: Aporte Literario. Ediciones Los Heraldos Negros.

Garcilaso de la Vega, I. (1943). Comentarios Reales de las Incas. Emecé Editores S.A.

Gilroy, P. (1993). The Black Atlantic. Modernity and Double Conciousness. Harvard University Press.

González, R. (1992). Contradanzas y latigazos. Editorial Letras Cubanas.

Meillassoux, C. (1979). Historical Modelities of the Exploitation and Overexplotation of Labor. Critique of Anthropology, (4), 7-16.

Pollak-Eltz, A. (2000). La esclavitud en Venezuela: un estudio histórico Cultural. Universidad Católica Andrés Bello.

Ramos Guédez, J (2019) La africanía en Venezuela: esclavizados, abolición y aportes culturales. Centro de Investigaciones Históricas de Venezuela.

Sanz, J. (2008). No podemos andar enseñando embustes como en la IV. La negra Matea no fue nodriza del libertador. Aporrea. https://www.aporrea.org/actualidad/a54208.html 
Silva, C. (2011). Fotografías de Amas de Leche en Bahía. Evidencia visual de los aportes Africanos a la familia esclavista en Brasil. Nómadas, (35), 119-137. http://nomadas.ucentral.edu.co/nomadas/ pdf/nomadas_35/35_7S_FotografiasdeamasdelecheenBahia.pdf

Vargas-Arenas, I. (2010). Mujeres en tiempos de cambio. Centro Nacional de Historia.

Vargas-Arenas, I. (2019). Historia, Mujer, Mujeres: Origen y desarrollo histórico de la exclusión social en Venezuela. Fondo Editorial Fundarte.

Velázquez, M. (2006). Mujeres de origen africano en la capital novohispana siglos XVII y XVIII. Instituto Nacional de Antropología e Historia.

Vergara, A. y Cosme, L. (2018). Demando mi libertad Mujeres negras y sus estrategias de resistencia en la Nueva Granada, Venezuela y Cuba, 1700-1800. Editorial Universidad Icesi. 